(Biochemistry, Article)

\title{
Unique retinal binding pocket of primate blue-sensitive visual pigment
}

Yuki Nonaka, ${ }^{1}$ Shunpei Hanai, ${ }^{1}$ Kota Katayama,,${ }^{1,2}$ Hiroo Imai, ${ }^{3}$ and Hideki Kandori ${ }^{1,2}$

1Department of Life Science and Applied Chemistry, Nagoya Institute of Technology, Showaku, Nagoya 466-8555, Japan; 2OptoBioTechnology Research Center, Nagoya Institute of Technology, Showa-ku, Nagoya 466-8555, Japan; ${ }^{3}$ Primate Research Institute, Kyoto University, Inuyama 484-8506, Japan

Correspondence author: Hideki Kandori, Department of Life Science and Applied Chemistry, Nagoya Institute of Technology, Showa-ku, Nagoya 466-8555, Japan. Phone and fax: 81-52735-5207. E-mail: kandori@ nitech.ac.jp.

Key words: Batho intermediate, monkey blue, photochromism, retinal chromophore, FTIR 


\begin{abstract}
The visual pigments of humans contain 11-cis retinal as the chromophore of light perception, and its photoisomerization to the all-trans form initiates visual excitation in our eyes. It is well known that three isomeric states of retinal (11-cis, all-trans, and 9-cis) are in photoequilibrium at very low temperatures such as $77 \mathrm{~K}$. Here we report the lack of formation of the 9-cis form in monkey blue (MB) at $77 \mathrm{~K}$, as revealed by light-induced difference FTIR spectroscopy. This indicates that the chromophore binding pocket of MB does not accommodate the 9-cis form, even though it accommodates the all-trans form by twisting the chromophore. Mutation of the blue-specific tyrosine at position 265 into tryptophan, which is highly conserved in other animal rhodopsins, led to formation of the 9-cis form in MB, suggesting that Y265 is one of the determinants of the unique photochemistry in blue pigments. We also found that 9-cis retinal does not bind to $\mathrm{MB}$ opsin, implying that the chromophore binding pocket does not accommodate the 9-cis form at physiological temperature. The unique property of $\mathrm{MB}$ is discussed based on the present results.
\end{abstract}


Humans have two kinds of vision: twilight vision mediated by rhodopsin in rod photoreceptor cells and color vision achieved by multiple color pigments in cone photoreceptor cells. ${ }^{1}$ Humans also possess three color pigments, red-, green-, and blue-sensitive proteins, that maximally absorb at 560, 530, and $425 \mathrm{~nm}$, respectively. ${ }^{2}$ Rhodopsin and color pigments both contain a common chromophore molecule, 11-cis retinal, and different chromophore-protein interactions allow preferential absorption of different colors. ${ }^{3,4}$ Purified proteins are a prerequisite to understanding the mechanism of color tuning and the activation process by light. Studying rhodopsin is highly advantageous because large amounts of protein can be obtained from vertebrate and invertebrate native cells. Bovine rhodopsin is a standard protein, and its crystal structures have been reported for the unphotolyzed state, ${ }^{5}$ opsin, ${ }^{6}$ photobleaching intermediates, ${ }^{7,8}$ active state,,${ }^{9,10}$ and the active-state complexed with the C-terminus peptide of the $\alpha$ subunit of G-protein, ${ }^{10-12}$ or engineered mini-Go, ${ }^{13}$ and arrestin. ${ }^{14}$ These structures have provided insight into the mechanism of the chromophore-protein interaction and activation.

On the other hand, structural studies of color pigments lag far behind those of rhodopsin. No color visual pigments have yet been crystallized. Under such circumstances, we started structural studies of primate color pigments by using low-temperature difference FTIR spectroscopy. ${ }^{15,16}$ To achieve this, monkey red- (MR), and monkey green- (MG)-sensitive color visual pigments were expressed in HEK cells, and light-induced difference FTIR spectra were measured at $77 \mathrm{~K}$, where the photoproduct, batho-intermediate (Batho), was reverted to the initial state by light. ${ }^{17-21}$ Consequently, photoconversions from the initial state to Batho, and Batho to the initial state were repeated. This photochromic property has been highly advantageous to improve the signal-to-noise ratio of FTIR spectra. Although a lower expression level was reported for blue-sensitive pigments, we successfully obtained light-induced difference FTIR spectroscopy of MB from marmoset. ${ }^{22}$

In the study of MR and MG, analysis of the 9-cis form was useful. In the study of bovine rhodopsin, it is well known that the 11-cis form (the unphotolyzed state), the all-trans form 
(Batho), and the 9-cis form (also called isorhodopsin) are in photoequilibrium at $77 \mathrm{~K},{ }^{23,24}$ indicating that the retinal binding pocket of bovine rhodopsin accommodates these three isomers. This is also the case for other visual pigments including MR and MG. ${ }^{17}$ In fact, a structural comparison between the 11-cis and 9-cis forms provided useful information of protein-bound water molecules in MR and MG. We reported that water $\mathrm{O}-\mathrm{D}$ stretching vibrations in $\mathrm{D}_{2} \mathrm{O}$ are identical in both 11-cis and 9-cis forms for bovine rhodopsin, ${ }^{24}$ suggesting the same hydrogenbonding networks. In contrast, in $\mathrm{MR}$ and $\mathrm{MG}$, we found different water $\mathrm{O}-\mathrm{D}$ stretching vibrations between the 11-cis and 9-cis forms, leading to positional identification of these protein-bound water molecules. ${ }^{18}$ When we published the first paper on $\mathrm{MB}$, we focused on the difference spectra between the 11-cis (unphotolyzed state) and all-trans (Batho) forms. ${ }^{22}$

In the present study, we attempted to stabilize the 9-cis form of MB at $77 \mathrm{~K}$. Initially UVvisible spectroscopy was used to study the photoequilibrium mixture at liquid air or nitrogen temperatures. $^{23,25-28}$ However, vibrational spectroscopy such as resonance Raman and IR spectroscopy is more suitable for this aim, as isomer-specific vibrations appear in the 1250-1150 $\mathrm{cm}^{-1}$ region, and since each isomer can be easily distinguished. ${ }^{24,29-35}$ Interestingly, when we illuminated $\mathrm{MB}$ at various wavelengths of light in this study, we could not observe the 9-cis form of $\mathrm{MB}$ at $77 \mathrm{~K}$. This indicates that the chromophore binding pocket of $\mathrm{MB}$ does not accommodate the 9-cis form, even though it does accommodate the all-trans form (Batho). Mutation of the blue-specific tyrosine at position 265 into tryptophan, which is highly conserved in other animal rhodopsins, led to formation of the 9-cis form in MB, suggesting that Y265 is the determinant of the unique photochemistry in blue pigments. We also found that 9-cis retinal did not bind to MB opsin, implying that the chromophore binding pocket does not accommodate the 9-cis form. The unique property of $\mathrm{MB}$ is discussed based on the present results.

\section{MATERIALS AND METHODS}


Sample Preparation. MB cDNA was tagged with the Rho1D4 epitope sequence and introduced into the pcDNA3.1 expression vector. This construct was expressed in the HEK cell line and regenerated with 11 -cis-retinal. ${ }^{22}$ MRh was prepared similarly. ${ }^{22}$ Site-directed mutagenesis was performed using the QuikChange Multisite-Directed Mutagenesis Kit (Agilent Technologies, Inc., Santa Clara, CA, USA). ${ }^{22}$ The regenerated sample was solubilized with a buffer containing $2 \%(\mathrm{w} / \mathrm{v}) n$-dodecyl- $\beta$-D-maltoside (DDM) (final concentration was $1 \%(\mathrm{w} / \mathrm{v})$ ), $50 \mathrm{mM}$ HEPES, $140 \mathrm{mM} \mathrm{NaCl}$, and $3 \mathrm{mM} \mathrm{MgCl}_{2}$ (pH 7.0) and purified by adsorption on an antibody-conjugated column and eluted with a buffer containing $0.10 \mathrm{mg} / \mathrm{mL}$ 1D4 peptide, 0.02\% DDM, $50 \mathrm{mM}$ HEPES, $140 \mathrm{mM} \mathrm{NaCl}$, and $3 \mathrm{mM} \mathrm{MgCl}_{2}(\mathrm{pH} 7.0)$.

Low-Temperature FTIR Spectroscopy. For FTIR spectroscopy, MB and MRh samples in detergent were reconstituted into phosphatidylcholine (PC) liposomes with a protein-to-lipid molar ratio of 1:30 by dialysis to remove DDM. The reconstituted sample was suspended in a buffer containing $2 \mathrm{mM}$ phosphate and $10 \mathrm{mM} \mathrm{NaCl}(\mathrm{pH} 7.25)$, placed onto a $\mathrm{BaF}_{2}$ window and dried with an aspirator. Low-temperature FTIR spectroscopy was applied to the films hydrated with $\mathrm{H}_{2} \mathrm{O}$ at $77 \mathrm{~K}$, as described previously. ${ }^{17,18,22}$

The MB samples were illuminated with $400 \mathrm{~nm}$ light (by using an interference filter) for 5 min at $77 \mathrm{~K}$, followed by illumination with $>520 \mathrm{~nm}$ light (by using a VO54 cut-off filter) for 5 min at $77 \mathrm{~K}^{22}$ The former and latter illuminations convert $\mathrm{MB}$ to Batho, and Batho to $\mathrm{MB}$, respectively, from which Batho (all-trans) minus MB (11-cis) difference FTIR spectra were obtained. To examine the 9-cis form, Batho was illuminated by using various cut-off filters such as VY47 (>450 nm light), VY46 (>440 nm light), and VY45 (>430 nm light). For each measurement, 128 interferograms were accumulated, and 40 recordings were averaged. FTIR spectra were recorded with a $2 \mathrm{~cm}^{-1}$ resolution. 
Hydroxylamine Bleach. HEK cells expressing each protein were divided into two, to which either 11-cis or 9-cis retinal was added and incubated for 1 hour. Then, the regenerated sample was solubilized with a buffer containing $2 \%(\mathrm{w} / \mathrm{v})$ DDM (final concentration was $1 \%(\mathrm{w} / \mathrm{v})$ ), 50 $\mathrm{mM}$ HEPES, $140 \mathrm{mM} \mathrm{NaCl}$, and $3 \mathrm{mM} \mathrm{MgCl} 2$ (pH 7.0). The DDM-solubilized proteins in the presence of $10 \mathrm{mM}$ hydroxylamine were kept for $30 \mathrm{~min}$ in the dark at $4^{\circ} \mathrm{C}$, and then illuminated with $>400 \mathrm{~nm}$ (the wild-type and mutant $\mathrm{MB}$ ) or $>480 \mathrm{~nm}$ (the wild-type and mutant MRh) light for $1.5 \mathrm{~min}$, respectively.

\section{RESULTS}

No Formation of the 9-cis Form in MB at $77 \mathrm{~K}$. The dotted lines in Figure 2a show lightminus-dark difference FTIR spectra upon formation of Batho from $M B, M R h, M G$, and $M R$, where positive and negative signals correspond to all-trans and 11-cis retinal, respectively. In these cases, Batho was formed by illumination of a monochromatic light from an interference filter (400 nm for MB, $501 \mathrm{~nm}$ for $\mathrm{MRh}$ and MG, and $543 \mathrm{~nm}$ for MR). ${ }^{22}$ On the other hand, photo-reversion was possible by illumination with light at longer wavelengths derived from a cut-off filter ( $>520 \mathrm{~nm}$ for $\mathrm{MB},>610 \mathrm{~nm}$ for $\mathrm{MRh}$ and $\mathrm{MG}$, and $>660 \mathrm{~nm}$ for $\mathrm{MR}$ ), which was evidenced by mirror-imaged difference spectra in the UV-visible or IR regions. ${ }^{22}$

While the dotted lines in Figure 2a originate only from all-trans and 11-cis forms, illumination of Batho with different wavelengths yields formation of the 9-cis form. For instance, the solid black line in Figure 2a represents the all-trans (Batho) minus 9-cis spectrum for MRh in which Batho was formed by illumination at $501 \mathrm{~nm}$, whereas the illumination of Batho with >540-nm light accumulated the 9-cis form. The reason is that the 9-cis form has the most blueshifted absorption, and its marker band is a peak at $1207 \mathrm{~cm}^{-1} \cdot 24,30,35$ The black spectrum in Figure $2 \mathrm{~b}$ is the double difference of the black dotted and solid spectra in Figure 2a, where positive and negative signals correspond to 9-cis and 11-cis retinal, respectively. This is also the case for the reported color visual pigments. To accumulate the 9-cis form, we established illumination 
wavelengths as $>540 \mathrm{~nm}$ and $>580 \mathrm{~nm}$ for $\mathrm{MG}$ and $\mathrm{MR}$, respectively, ${ }^{18}$ and the 9 -cis-specific vibrational band at $1207 \mathrm{~cm}^{-1}\left(1208 \mathrm{~cm}^{-1}\right.$ for MR) was used to optimize the experimental conditions.

When converting wavelengths from Batho into 9-cis and 11-cis forms, the difference was $70 \mathrm{~nm}$ for $\mathrm{MRh}$ and $\mathrm{MG}$, and $80 \mathrm{~nm}$ for MR. In the present study, we attempted to accumulate the 9-cis form for MB similarly at $77 \mathrm{~K}$. However, we found an unusual photochemical property for MB. The solid blue line in Figure 2a is the difference FTIR spectrum obtained by illuminating Batho at $>430 \mathrm{~nm}$ for $\mathrm{MB}$, which coincides with the spectrum obtained by illuminating Batho at $>520 \mathrm{~nm}$ for MB. This unique property of MB can be easily seen in Figure $2 \mathrm{~b}$, where the 9-cisspecific $1207 \mathrm{~cm}^{-1}$ bands were seen for MRh, MG, and MR, but not for MB.

Y265 is Responsible for the Absence of the 9-cis Form in MB at 77 K. Animal rhodopsins generally exhibit photoequilibria of the 11-cis, all-trans, and 9-cis forms at $77 \mathrm{~K} .^{3}$ In contrast, the 9-cis form did not form in $\mathrm{MB}$ at $77 \mathrm{~K}$, suggesting a unique chromophore binding pocket in MB. Figure 3 compares the 19 amino acids surrounding the retinal chromophore among MB, MG, MR, and MRh, based on the structure of bovine rhodopsin. ${ }^{5}$ It should be noted that W265 is highly conserved in animal rhodopsins including long ( $\mathrm{L}$ group) and middle ( $\mathrm{M}$ group) wavelength sensitive color visual pigments. ${ }^{3,4}$ In contrast, the corresponding residue of W265 is tyrosine in short wavelength sensitive color visual pigments (S group). Therefore, in this study, we mutated Y265 of MB into tryptophan, and W265 of MRh into tyrosine.

Figure 4a clearly shows the dependence of illumination wavelength on Y265W MB, where dotted (400 nm and >520 nm lights) and solid (400 nm and >430 nm lights) lines differ significantly. The double difference spectrum in Figure $4 \mathrm{~b}$ possesses a positive peak at $1201 \mathrm{~cm}^{-}$ 1, which has a different frequency from the 9-cis-specific band at $1207 \mathrm{~cm}^{-1}$ (Figure 3). Therefore, this is not a direct indication of the formation of the 9-cis state. Nevertheless, the present results clearly indicate a photoequilibrium of the three states, and it is reasonable to consider the 9-cis 
form as the third state in addition to the 11-cis (unphotolyzed) and all-trans (Batho) states. In this case, the peak frequency at $1201 \mathrm{~cm}^{-1}$ suggests that the 9-cis chromophore is not in a relaxed conformation. Another possibility is that the third state contains the 11-cis chromophore, whose absorption is blue-shifted from the fully relaxed 11-cis form. From the present observation, we conclude that the residue at position 265 contributes to the unique property of MB.

In the case of MRh, the W265Y mutant exhibited similar spectral features to those of the wild-type protein (Figure 4a). In fact, a clear positive peak appeared at $1209 \mathrm{~cm}^{-1}$ in the double difference spectrum (Figure $4 \mathrm{~b}$ ). No conversion of MRh to the MB-specific property by this mutation suggests that the amino acid at position 265 is not the only determinant to produce the 9-cis form.

No Pigment Formation from 9-cis Retinal and MB Opsin. The lack of formation of the 9cis pigment at $77 \mathrm{~K}$ raised another issue, whether pigment could form from 9-cis retinal and $\mathrm{MB}$ opsin at room temperature. To clarify this, we divided HEK cells expressing MB into two, to which either 11-cis or 9-cis retinal was added. Then, the regenerated sample was solubilized by $1 \% \mathrm{DDM}$ and illuminated in the presence of $10 \mathrm{mM}$ hydroxylamine. Figure 5 shows the results of hydroxylamine bleach for the wild-type proteins of MB (a) and MRh (b), where dotted and solid lines represent the results for 11-cis and 9-cis retinal, respectively. When 11-cis retinal (dotted lines) was added, MB and MRh formed, and their absorption maxima are located at 430 and $499 \mathrm{~nm}$, respectively. On the other hand, the 9-cis pigment did not form for MB (a), whereas 9-cis rhodopsin (isorhodopsin) formed for MRh, whose absorption maximum is located at 485 $\mathrm{nm}$. The present results imply that the retinal binding pocket of MB does not accommodate 9cis retinal, unlike other visual pigments.

We also applied similar experiments to Y265W MB and W265Y MRh. These results, which are shown in Figure 6, were identical to the wild-type. Namely, retinal binding was observed for the 11-cis form of MB (dotted line in Figure 6a), and the 11-cis (dotted line in Figure 6b) and 9- 
cis (solid line in Figure 6b) forms of MRh, but not for 9-cis in MB (solid line in Figure 6a). Therefore, the Y265W mutation was not sufficient for pigment formation from 9-cis retinal and MB.

\section{DISCUSSION}

The retinal binding pocket is unique for visual pigments. In general, 11-cis retinal is not thermally stable and easily isomerizes into the all-trans form. On the other hand, 11-cis retinal is very stable in animal rhodopsins, indicating that the retinal binding pocket optimally accommodates the 11-cis form. Nevertheless, the 11-cis to all-trans photoisomerization takes places even at $77 \mathrm{~K},{ }^{23,24}$ where the protein environment is frozen. This is consistent with ultrafast retinal photoisomerization ${ }^{36-40}$ during which there is no time for the protein environment to change its structure. Note that the shapes of 11-cis and all-trans retinals differ, as shown in Figure 1. Therefore, the mechanism of retinal photoisomerization has been a long-standing issue in the study of vision. ${ }^{3,41,42}$

It is well known that the retinal binding pocket accommodates the 9-cis form in addition to the 11-cis and all-trans forms at $77 \mathrm{~K}$. This is also the case for other visual pigments including MR and MG. ${ }^{18}$ However, the present study clearly demonstrates that the 9-cis form was not produced by illuminating 11-cis and all-trans forms in MB. It should be noted that the 9-cis form was produced for chicken blue-sensitive pigment at $77 \mathrm{~K} .{ }^{28}$ Whereas chicken blue belongs to the M1-group, and chicken violet-sensitive pigment is in the S-group. ${ }^{43}$ A previous resonance Raman study attempted to answer the question "why are blue visual pigments blue?", in which the 9-cis form was produced for the 440-nm absorbing pigment of the toad (Bufo marinus) at 77 $\mathrm{K},{ }^{44}$ although this pigment is not in the S-group. Thus we suggest that this property is unique to visual pigments in the S-group.

In the present study, we also showed that 9-cis retinal was not bound to MB opsin, which is also in striking contrast to other visual pigments. The lack of pigment formation from 9-cis 
retinal and human blue opsin was already reported in 1999, even though no data was shown. ${ }^{45}$ Therefore, it is likely that the unique retinal binding pocket is common for the S-group. Interestingly, it was revealed that 11-cis-locked 6-membered-ring retinal can be bound for human blue opsin, but neither for human green nor red opsin. ${ }^{46}$ These results also emphasize the uniqueness of the S-group.

These unique properties of the S-group originate from the amino acids that surround the retinal chromophore. The residues around the retinal chromophore based on the structure of bovine rhodopsin are shown in Figure 3, from which Y265 was found to play an important role in photoequilibrium at $77 \mathrm{~K}$ (Figure 4). A previous study with 11-cis-locked 6-membered-ring retinal also concluded that Y265 contributes significantly. ${ }^{46}$ The crystal structures of bovine rhodopsin ${ }^{5}$ and 9 -cis rhodopsin ${ }^{47}$ in Figure 7 depict the unique position of W265, which is located at the bending region of the retinal chromophore. While the important role of position 265 is not in doubt, the present study also elucidated the contributions of positions other than position 265. Further experimental and theoretical studies are needed to clarify the unique chromophoreprotein interaction in the S-group.

\section{ACKNOWLEDGEMENTS}

This work was financially supported by grants from the Japanese Ministry of Education, Culture, Sports, Science and Technology to K.K. (18K14662) and H.K. (18H03986, 19H04959), and from the Japan Science and Technology Agency (JST), PRESTO to K.K. (JPMJPR19G4). This work was partly supported by the JSPS Core-to-Core Program, A. Advanced Research Networks (Wildlife Research Center of Kyoto University).

\section{Conflicts of Interest}

All authors declare no conflicts of interest. 


\section{REFERENCES}

(1) Wald, G. (1968) Molecular basis of visual excitation. Science 162, 230-239.

(2) Nathans, J., Thomas, D., and Hogness, D. S. (1986) Molecular genetics of human color vision: the genes encoding blue, green and red pigments. Science 232, 193-202.

(3) Ernst, O. P., Lodowski, D. T., Elstner, M., Hegemann, P., Brown, L. S., and Kandori, H. (2014) Microbial and animal rhodopsins: structures, functions, and molecular mechanisms. Chem. Rev. 114, 126-163.

(4) Imamoto, Y., and Shichida, Y. (2014) Cone visual pigments. Biochim. Biophys. Acta $1837,664-673$.

(5) Palczewski, K., Kumasaka, T., Hori, T., Behnke, C. A., Motoshima, H., Fox, B. A., Le Trong, I., Teller, D. C., Okada, T., Stenkamp, R. E., Yamamoto, M., and Miyano, M. (2000) Crystal structure of rhodopsin: A G protein-coupled receptor. Science 289, 739745.

(6) Park, J. H., Scheerer, P., Hofmann, K. P., Choe, H. W., and Ernst, O. P. (2008) Crystal structure of the ligand-free G-protein-coupled receptor opsin. Nature 454, 183-187.

(7) Nakamichi, H., and Okada, T. (2006) Crystallographic analysis of primary visual photochemistry. Angew. Chem. Int. Ed. Engl. 45, 4270-4273.

(8) Nakamichi, H., and Okada, T. (2006) Local peptide movement in the photoreaction intermediate of rhodopsin. Proc. Natl. Acad. Sci. U. S. A. 103, 12729-12734.

(9) Standfuss, J., Edwards, P. C., D’Antona, A., Fransen, M., Xie, G., Oprian, D. D., and Schertler, G. F. (2011) The structural basis of agonist-induced activation in constitutively active rhodopsin. Nature 471, 656-660.

(10) Choe, H. W., Kim, Y. J., Park, J. H., Morizumi, T., Pai E. F., Krauss, N., Hofmann, K.P., Scheerer, P., and Ernst, O. P. (2011) Crystal structure of metarhodopsin II. Nature 471, 651-655. 
(11) Deupi, X., Edwards, P., Singhai, A., Nickle, B., Oprian, D., Schertler, G., and Standfuss, J. (2012) Stabilized G protein binding site in the structure of constitutively active metarhodopsin-II. Proc. Natl. Acad. Sci. U. S. A. 109, 119-124.

(12) Scheerer, P., Park, J. H., Hildebrand P. W., Kim, Y. J., Krauss, N., Choe, H. W., Hofmann, K. P., and Ernst, O. P. (2008) Crystal structure of opsin in its G-protein-interacting conformation. Nature 455, 497-502.

(13) Tsai, C. J., Pamula, F., Nehmé, R., Mühle, J., Weinert, T., Flock, T., Nogly, P., Edwards, P. C., Carpenter, B., Gruhl, T., Ma, P., Deupi, X., Standfuss, J., Tate, C. G., and Schertler, G. F. X. (2018) Crystal structure of rhodopsin in complex with a mini- $\mathrm{G}_{\mathrm{o}}$ sheds light on the principles of $\mathrm{G}$ protein selectivity. Sci. Adv. 4, eaat7052.

(14) Kang, Y., Zhou, X. E., Gao, X., He, Y., Liu, W., Ishchenko, A., Barty, A., White, T. A., Yefanov, O., Han, G. W., Xu, Q., de Waal, P. W., Ke, J., Tan, M. H., Zhang, C., Moeller, A., West, G. M., Pascal, B. D., Van Eps, N., Caro, L. N., Vishnivetskiy, S. A., Lee, R. J., Suino-Powell, K. M., Gu, X., Pal, K., Ma, J., Zhi, X., Boutet, S., Williams, G. J., Messerschmidt, M., Gati, C., Zatsepin, N. A., Wang, D., James, D., Basu, S., RoyChowdhury, S., Conrad, C. E., Coe, J., Liu, H., Lisova, S., Kupitz, C., Grotjohann, I., Fromme, R., Jiang, Y., Tan, M., Yang, H., Li, J., Wang, M., Zheng, Z., Li, D., Howe, N., Zhao, Y., Standfuss, J., Diederichs, K., Dong, Y., Potter, C. S., Carragher, B., Caffrey, M., Jiang, H., Chapman, H. N., Spence, J. C, Fromme, P., Weierstall, U., Ernst, O. P., Katritch, V., Gurevich, V. V., Griffin, P. R., Hubbel, W. L., Stevens, R. C., Cherezov, V., Melcher, K., and Xu, H. E. (2015) Crystal structure of rhodopsin bound to arrestin by femtosecond X-ray laser. Nature 523, 561-567.

(15) Kandori, H., and Katayama, K. (2020) Light-induced difference FTIR spectroscopy of photoreceptive proteins. In: Vibrational Spectroscopy in Protein Research, From Purified Proteins to Aggregates and Assemblies (Ozaki, Y., Baranska, M., Lednev, I. and Wood, B., Ed.) 1st ed., Academic Press, New York. in press. 
(16) Kandori, H. (2020) Structure/function study of photoreceptive proteins by FTIR spectroscopy. Bull. Chem. Soc. Jpn. in press.

(17) Katayama, K., Furutani, Y., Imai, H., and Kandori, H. (2010) An FTIR study of monkey green- and red-sensitive visual pigments. Angew. Chem. Int. Ed. Engl. 49, 891-894.

(18) Katayama, K., Furutani, Y., Imai, H., and Kandori, H. (2012) Protein-bound water molecules in primate red- and green-sensitive visual pigments. Biochemistry 51, 11261133.

(19) Katayama, K., Okitsu, T., Imai, H., Wada, A., and Kandori, H. (2015) Identical hydrogen-bonding strength of the retinal Schiff base between primate green- and redsensitive pigments: new insight into color tuning mechanism. J. Phys. Chem. Lett. 6, $1130-1133$.

(20) Katayama, K., Nakamura, S., Sasaki, T., Imai, H., and Kandori, H. (2019) Role of Gln114 in spectral tuning of a long-wavelength sensitive visual pigment. Biochemistry 58, 2944 2952.

(21) Katayama, K., Imai, H., and Kandori, H. (2019) FTIR Study of S180A mutant of primate red-sensitive pigment. Chem. Lett. 48, 1142-1144.

(22) Katayama, K., Nonaka, Y., Tsutsui, K., Imai, H., and Kandori, H. (2017) Spectral tuning mechanism of primate blue-sensitive visual pigment elucidated by FTIR spectroscopy. Sci. Rep. 7, 4904.

(23) Yoshizawa, T., and Wald, G. (1963) Pre-lumirhodopsin and the bleaching of visual pigments. Nature 197, 1279-1286.

(24) Kandori, H., and Maeda, A. (1995) FTIR spectroscopy reveals microscopic structural changes of the protein around the rhodopsin chromophore upon photoisomerization. Biochemistry 34, 14220-14229. 
(25) Imai, H., Imamoto, Y., Yoshizawa, T., and Shichida, Y. (1995) Difference in molecular properties between chicken green and rhodopsin as related to the functional difference between cone and rod photoreceptor cells. Biochemistry 34, 10525-10531.

(26) Imamoto, Y., Sakai, M., Katsuta, Y., Wada, A., Ito, M., and Shichida, Y. (1996) Structure around C6-C7 bond of the chromophore in bathorhodopsin: low-temperature spectroscopy of 6s-cis-locked bicyclic rhodopsin analogs. Biochemistry 35, 6257-6262.

(27) Imamoto, Y., Yoshizawa, T., and Shichida, Y. (1996) Chromophore configuration of iodopsin and its photoproducts formed at low temperatures. Biochemistry 35, 1459914607.

(28) Imai, H., Terakita, A., Tachibanaki, S., Imamoto, Y., Yoshizawa, T., and Shichida, Y. (1997) Photochemical and biochemical properties of chicken blue-sensitive cone visual pigment. Biochemistry 36, 12773-12779.

(29) Eyring, G., and Mathies, R. (1979) Resonance Raman studies of bathorhodopsin: evidence for a protonated Schiff base linkage. Proc Natl Acad Sci U S A.76, 33-37.

(30) Eyring, G., Curry, B., Mathies, R., Fransen, R., Palings, I., and Lugtenburg, J. (1980) Interpretation of the resonance Raman spectrum of bathorhodopsin based on visual pigment analogues. Biochemistry 19, 2410-2418.

(31) Siebert, F., Mäntele, W., and Gerwert, K. (1983) Fourier-transform infrared spectroscopy applied to rhodopsin. The problem of the protonation state of the retinylidene Schiff base re-investigated. Eur J Biochem. 136, 119-27.

(32) Bagley, K. A., Balogh-Nair, V., Croteau, A. A., Dollinger, G., Ebrey, T. G., Eisenstein, L., Hong, M. K., Nakanishi, K., and Vittitow, J. (1985) Fourier-transform infrared difference spectroscopy of rhodopsin and its photoproducts at low temperature. Biochemistry 24, 6055-6071.

(33) DeGrip, W. J., Gray, D., Gillespie, J., Bovee, P. H., Van den Berg, E. M., Lugtenburg, J., and Rothschild, K. J. (1988) Photoexcitation of rhodopsin: conformation changes in 
the chromophore, protein and associated lipids as determined by FTIR difference spectroscopy. Photochem Photobiol. 48, 497-504

(34) Imamoto, Y., Hirano, T., Imai, H., Kandori, H., Maeda, A., Yoshizawa, T., Groesbeek, M., Lugtenburg, J., and Shichida, Y. (1999) Effect of anion binding on iodopsin studied by low-temperature Fourier transform infrared spectroscopy. Biochemistry 38, 1174911754.

(35) Hirano, T., Fujioka, N., Imai, H., Kandori, H., Wada, A., Ito, M., and Shichida, Y. (2006) Assignment of the vibrational modes of the chromophores of iodopsin and bathoiodopsin: low-temperature Fourier transform infrared spectroscopy of ${ }^{13} \mathrm{C}$ - and ${ }^{2} \mathrm{H}$ labeled iodopsins. Biochemistry 45, 1285-1294.

(36) Busch, G. E., Applebury, M. L., Lamola, A. A., and Rentzepis, P. M. (1972) Formation and decay of prelumirhodopsin at room temperatures. Proc Natl Acad Sci U S A. 69, 2802-2806.

(37) Kandori, H., Mizukami, T., Okada, T., Imamoto, Y., Fukada, Y., Shichida, Y., and Yoshizawa, T. (1990) Bathoiodopsin, a primary intermediate of iodopsin at physiological temperature. Proc Natl Acad Sci U S A. 87, 8908-8912.

(38) Schoenlein, R. W., Peteanu, L. A., Mathies, R. A., and Shank, C. V. (1991) The first step in vision: femtosecond isomerization of rhodopsin. Science 254, 412-415.

(39) Chosrowjan, H., Mataga, N., Shibata, Y., Tachibanaki, S., Kandori, H., Shichida, Y., Okada, T., and Kouyama, T. (1998) Rhodopsin emission in real time: a new aspect of the primary event in vision. J. Am. Chem. Soc. 120, 9706-9707.

(40) Polli, D., Altoè, P., Weingart, O., Spillane, K. M., Manzoni, C., Brida, D., Tomasello, G., Orlandi, G., Kukura, P., Mathies, R. A., Garavelli, M., and Cerullo, G. (2010) Conical intersection dynamics of the primary photoisomerization event in vision. Nature 467, $440-443$. 
(41) Kandori, H., Shichida, Y., and Yoshizawa, T. (2001) Photoisomerization in rhodopsin. Biochemistry (Mosc) 66, 1197-1209.

(42) Gozem, S., Luk, H. L., Schapiro, I., and Olivucci, M. (2017) Theory and simulation of the ultrafast double-bond isomerization of biological chromophores. Chem Rev. 117, 13502-13565.

(43) Okano, T., Kojima, D., Fukada, Y., Shichida, Y., and Yoshizawa, T. (1992) Primary structures of chicken cone visual pigments: vertebrate rhodopsins have evolved out of cone visual pigments. Proc Natl Acad Sci U S A. 89, 5932-5936.

(44) Loppnow, G. R., Barry, B. A., and Mathies, R. A. (1989) Why are blue visual pigments blue? A resonance Raman microprobe study. Proc Natl Acad Sci U S A. 86, 1515-1518. Fasick, J. I., Lee, N., and Oprian, D. D. (1999) Spectral tuning in the human blue cone pigment. Biochemistry 38, 11593-11596.

(46) Katayama, K,, Gulati, S., Ortega, J. T., Alexander, N. S., Sun, W., Shenouda, M. M., Palczewski, K., and Jastrzebska, B. (2019) Specificity of the chromophore-binding site in human cone opsins. J Biol Chem. 294, 6082-6093

(47) Nakamichi, H., Buss, V., and Okada, T. (2007) Photoisomerization mechanism of rhodopsin and 9-cis-rhodopsin revealed by x-ray crystallography. Biophys. J. 92, L106L108. 


\section{FIGURE LEGENDS}

\section{Figure 1:}

Schematic drawing of the photoequilibria in MR, MG, MB, and MRh. The unphotolyzed state contains the 11-cis form, while illumination leads to photoequilibria mainly containing the alltrans form (Batho-intermediate) or the 9-cis form. Illumination wavelengths were established for MR MG, and MRh. On the other hand, photoequilibria were only investigated between the 11-cis and all-trans forms for $\mathrm{MB} .^{22}$

\section{Figure 2:}

(a) Light-minus-dark difference FTIR spectra in the $1300-1100 \mathrm{~cm}^{-1}$ region for $\mathrm{MB}, \mathrm{MRh}, \mathrm{MG}$, and MR at $77 \mathrm{~K}$. Dotted lines were obtained by the repeated illuminations of $400 \mathrm{~nm}$ and $>520$ $\mathrm{nm}$ lights for MB (blue line), $501 \mathrm{~nm}$ and >610 nm lights for MRh (black line) and MG (green line), and $543 \mathrm{~nm}$ and >660 $\mathrm{nm}$ lights for MR (red line). Solid lines were obtained by the repeated illuminations of $400 \mathrm{~nm}$ and >430 nm lights for MB (blue line), $501 \mathrm{~nm}$ and >540 nm lights for MRh (black line) and MG (green line), and $543 \mathrm{~nm}$ and >580 nm lights for MR (red line). In the case of MRh, MG, and MR, dotted and solid lines correspond to the all-trans minus 11-cis, and all-trans minus 9-cis difference spectra, respectively. (b) Double difference spectra in (a), where the solid line was subtracted from the dotted line. In the case of MRh, MG, and MR, this corresponds to the 9-cis minus 11-cis difference spectra.

\section{Figure 3:}

The amino acid residues surrounding the retinal chromophore in bovine rhodopsin (<4 A, PDB: 1U19), ${ }^{5}$ and the corresponding residues in MB, MG, MR and monkey rhodopsin.

\section{Figure 4:}


(a) Light-minus-dark difference FTIR spectra in the $1300-1100 \mathrm{~cm}^{-1}$ region for MB, Y265W MB, W265Y MRh, and MRh at $77 \mathrm{~K}$. Repeated illumination conditions for dotted lines are $400 \mathrm{~nm}$ and >520 nm lights for MB and Y265W MB (blue line), and $501 \mathrm{~nm}$ and >610 $\mathrm{nm}$ lights for W265Y MRh and MRh (black line). Repeated illumination conditions for solid lines are $400 \mathrm{~nm}$ and >430 nm lights for MB and Y265W MB (blue line), and $501 \mathrm{~nm}$ and >540 nm lights for W265Y MRh and MRh (black line). (b) Double difference spectra in (a), where the solid line was subtracted from the dotted line.

\section{Figure 5:}

Difference UV-visible spectra of MB (blue line) and MRh (black line) by hydroxylamine bleach, where positive and negative absorption spectra originate from the unphotolyzed state and retinal oxime, respectively. Dotted and solid lines represent the results for 11-cis and 9-cis retinal, respectively. The DDM (final conc.: 1\%)-solubilized proteins in the presence of $10 \mathrm{mM}$ hydroxylamine were kept for $30 \mathrm{~min}$ in the dark at $4^{\circ} \mathrm{C}$, and then illuminated with $>400 \mathrm{~nm}$ (MB) or $>480 \mathrm{~nm}(\mathrm{MRh})$ light for $1.5 \mathrm{~min}$.

\section{Figure 6:}

Difference UV-visible spectra of the mutant of position 265 for MB (Y265W MB; blue line) and MRh (W265Y MRh; black line) by hydroxylamine bleach, where positive and negative absorption spectra originate from the unphotolyzed state and retinal oxime, respectively. Dotted and solid lines represent the results for 11-cis and 9-cis retinal, respectively. The DDM (final conc.: 1\%)-solubilized proteins in the presence of $10 \mathrm{mM}$ hydroxylamine were kept for $30 \mathrm{~min}$ in the dark at $4^{\circ} \mathrm{C}$, and then illuminated with $>400 \mathrm{~nm}(\mathrm{Y} 265 \mathrm{~W} \mathrm{MB})$ or $>460 \mathrm{~nm}(\mathrm{~W} 265 \mathrm{Y} \mathrm{MRh})$ light for $1.5 \mathrm{~min}$.

\section{Figure 7:}


bioRxiv preprint doi: https://doi.org/10.1101/2020.05.29.123463; this version posted May 31, 2020. The copyright holder for this preprint (which was not certified by peer review) is the author/funder. All rights reserved. No reuse allowed without permission.

Structure of the chromophore and W265 in bovine rhodopsin containing 11-cis retinal (green;

PDB: 1U19), ${ }^{5}$ and 9-cis retinal (red; PDB: 2PED). 


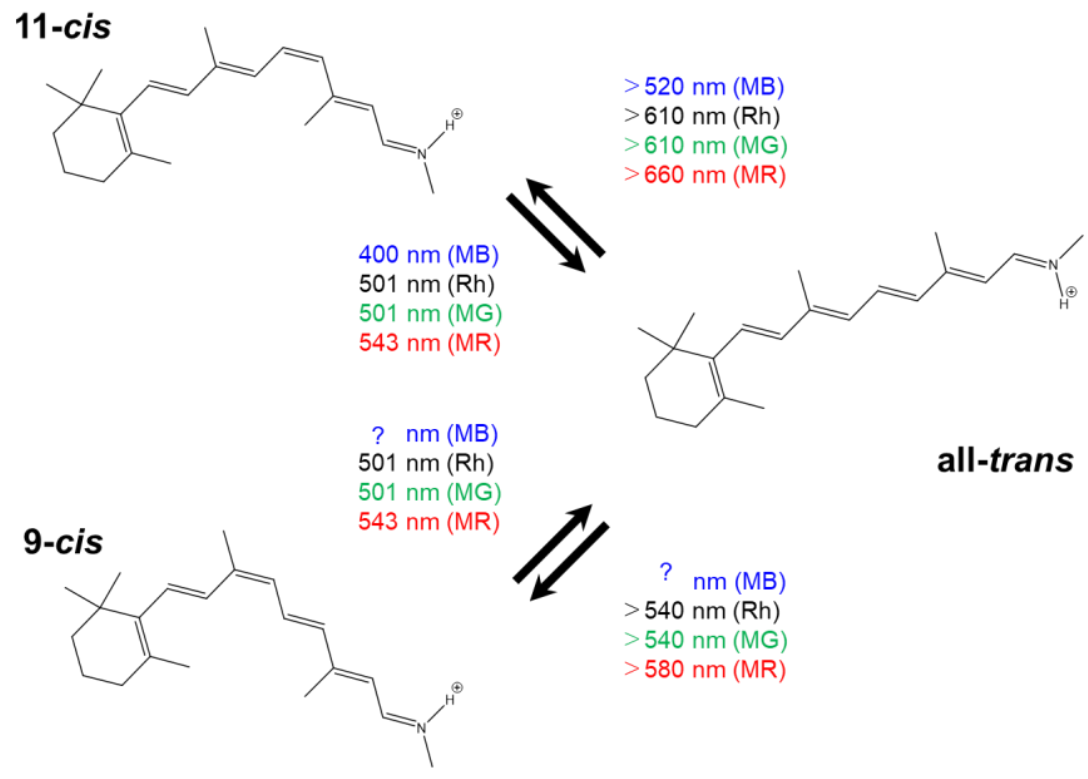

Figure.1 


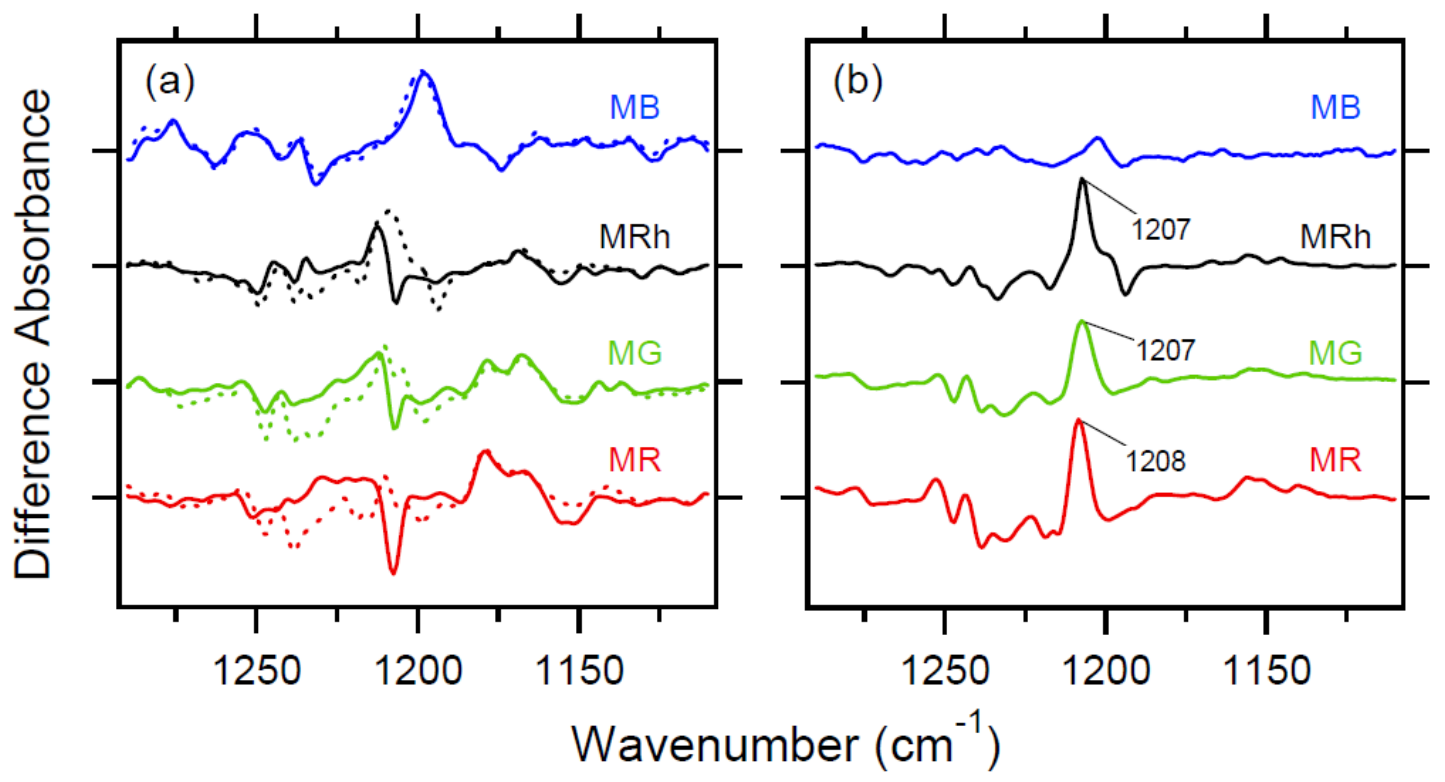

Figure.2 
bioRxiv preprint doi: https://doi.org/10.1101/2020.05.29.123463; this version posted May 31, 2020. The copyright holder for this preprint (which was not certified by peer review) is the author/funder. All rights reserved. No reuse allowed without permission.

\begin{tabular}{|c|c|c|c|c|c|c|c|c|c|c|c|c|c|c|c|c|c|c|c|c|c|c|}
\hline \multicolumn{1}{c}{113} & 117 & 118 & 121 & 122 & 186 & 187 & 188 & 189 & 191 & 207 & 211 & 212 & 261 & 265 & 268 & 269 & 292 & 296 \\
\hline Blue & E & G & T & G & L & S & C & G & P & W & L & C & F & F & Y & Y & A & A & K \\
\hline Green & E & V & S & G & I & S & C & G & P & V & L & C & C & F & W & Y & A & A & K \\
\hline Red & E & V & S & G & I & S & C & G & P & V & L & C & C & Y & W & Y & T & A & K \\
\hline Rhodopsin & E & A & T & G & E & S & C & G & I & Y & M & H & F & F & W & Y & A & A & K \\
\hline
\end{tabular}

Figure.3 


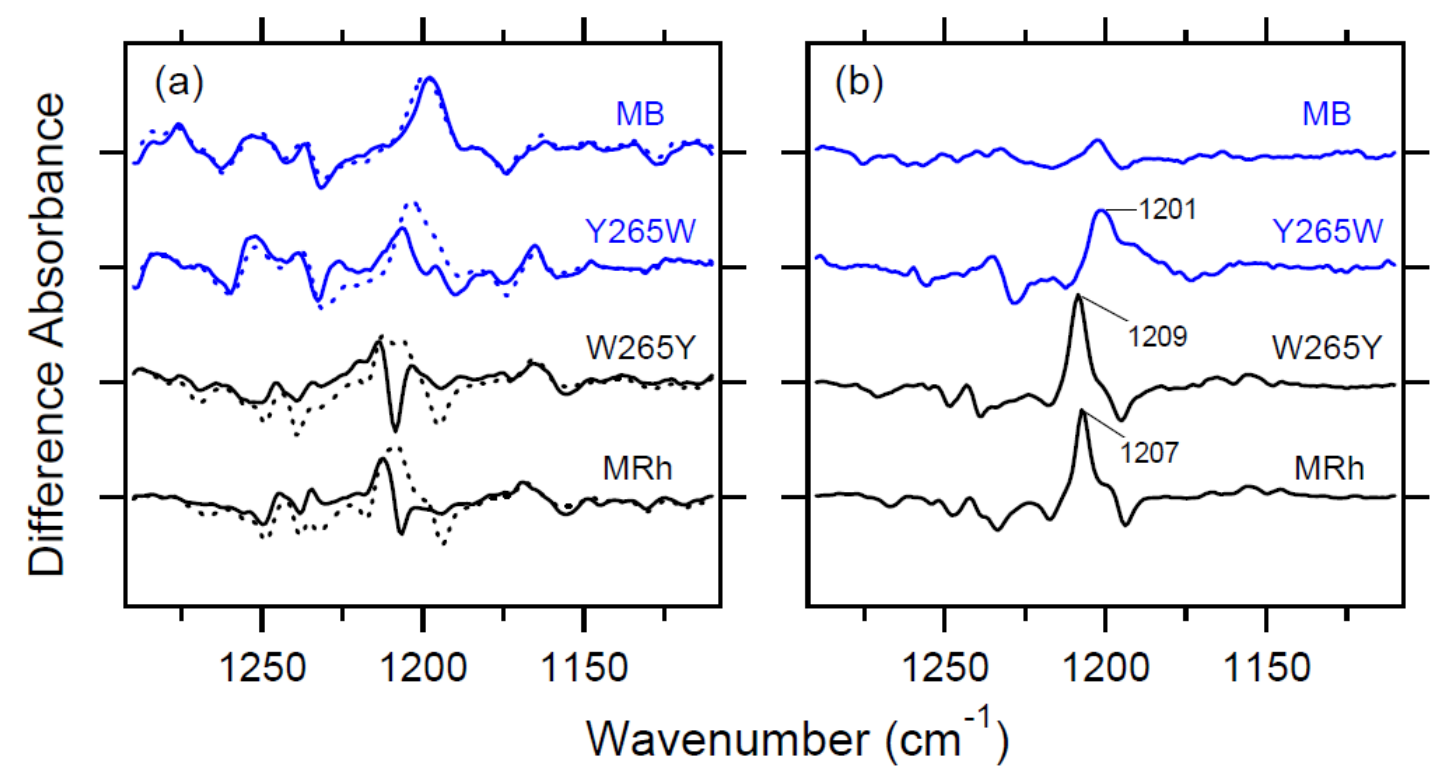

Figure.4 


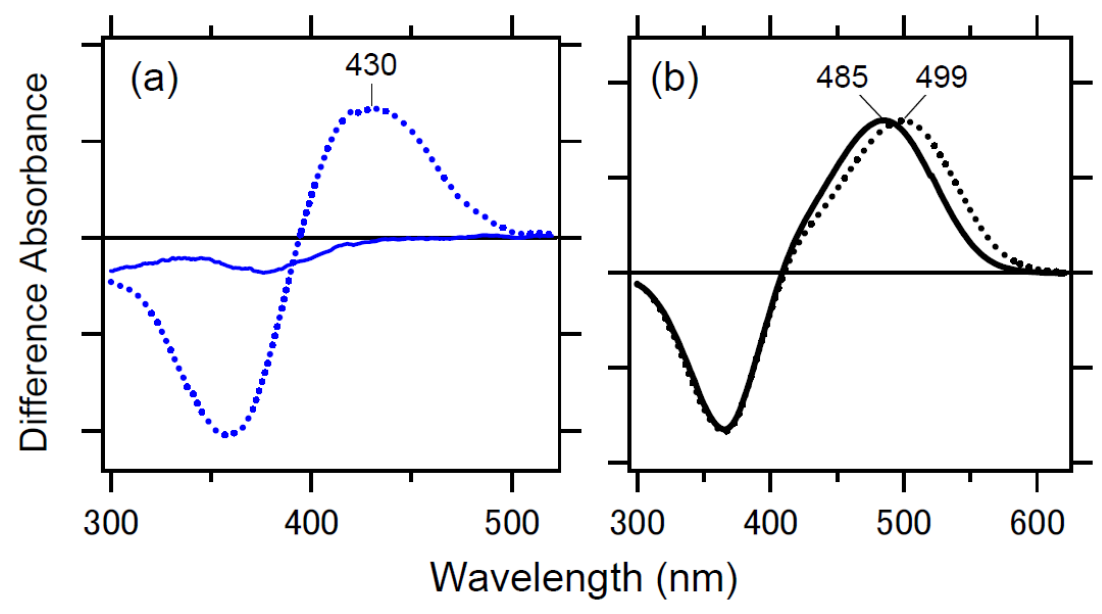

Figure.5 


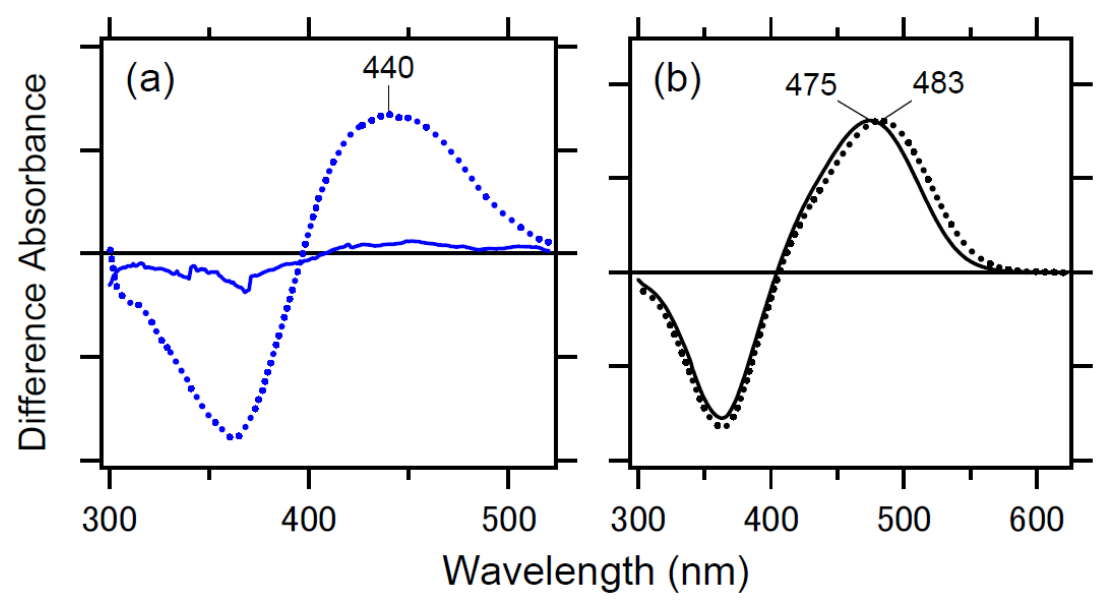

Figure.6 
bioRxiv preprint doi: https://doi.org/10.1101/2020.05.29.123463; this version posted May 31, 2020. The copyright holder for this preprint (which was not certified by peer review) is the author/funder. All rights reserved. No reuse allowed without permission.

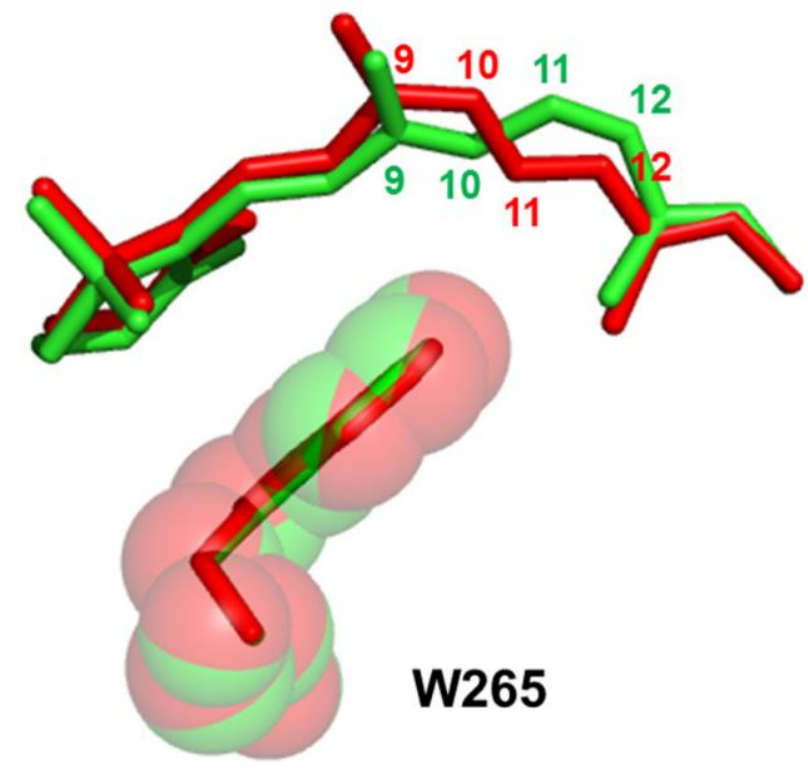

Figure.7 